\title{
Immune response to a Murray Valley encephalitis virus epitope expressed in the flagellin of an attenuated strain of Salmonella
}

\author{
BELINDA L. WHITTLE, EVA LEE, RON C. WEIR and NARESH K. VERMA \\ Division of Biochemistry and Molecular Biology, Faculty of Science, Australian National University, Canberra, \\ ACT 0200, Australia
}

\begin{abstract}
Recent developments in vaccine construction include the use of attenuated, avirulent strains of Salmonella as carriers of foreign antigens. These recombinant strains can elicit a heterologous immune response when injected into animals, demonstrating potential for their use in the construction of many vaccines. In the present study, a B-cell epitope of Murray Valley encephalitis virus (MVE) was identified and expressed in a Salmonella strain to evaluate its potential to induce a specific immune response to MVE. A synthetic oligonucleotide encoding the B-cell epitope (residues $\mathbf{E}_{201-224}$ ) of the envelope protein of MVE was inserted into the cloned flagellin gene of the Salmonella strain. The construct was sequenced to ensure correct orientation of the epitope. Expression of the epitope was demonstrated by Western blot analysis and immunogold electron microscopy with monoclonal antibody specific to the epitope. Electron microscopy analysis revealed multiple copies of the epitope along the flagella. The recombinant Salmonella carrying the hybrid flagellin gene elicited an immune response to the MVE epitope in a mouse model. The MVE-specific antibodies partially neutralised the virus in vitro. The significance of this system for engineering vaccines for other medically important flaviviruses is discussed.
\end{abstract}

\section{Introduction}

Recent developments in vaccine construction include the use of attenuated, avirulent strains of Salmonella as vectors carrying foreign antigens which elicit protective immune responses $[1,2]$. One important group of nonreverting Salmonella vaccine strains comprises the mutants dependent on aromatic compounds ( $\mathrm{aro}^{-}$) [3]. The aro ${ }^{-}$mutants have a deletion in one of the genes of the aromatic amino acids biosynthesis pathway resulting in strains dependent on aromatic compounds that are available in limited amounts in host tissues. The insertion of a tetracycline resistance transposon, $T n 10$, into the aroA gene of Salmonella serotype Typhimurium produced aroA strain SL3261 $[4,5]$, a well-defined aro $^{-}$mutant $[6,7]$. The aro mutants multiply only for a few generations in host tissues, but do persist in the spleen and liver for several weeks, inducing strong humoral and cellular immune responses [7,8]. A further development has been the insertion of synthetic oligonucleotides, encoding foreign epitopes, into a cloned Salmonella flagellin gene

Received 10 April 1996; accepted 15 June 1996. Corresponding author: B. L. Whittle.
$[3,9]$. A plasmid, pLS408, containing the H1-d flagellin gene of serotype Muenchen, has been constructed [10]. In this plasmid, a 48-bp deletion has been made in the hypervariable segment (region IV) of the flagellin gene. The remaining EcoRV site allows the blunt end insertion of oligonucleotides. T-cell epitopes have previously been expressed in the flagellin and the immune response to the epitopes examined in mice immunised with the recombinant Salmonella strain $[11,12]$. A number of epitopes of viral and eukaryotic origin have also been expressed in salmonella flagellin. In most cases, such recombinant Salmonella strains induced specific immune responses to the foreign epitopes $[3,13]$.

Murray Valley encephalitis virus (MVE) belongs to the flavivirus family of small enveloped, singlestranded RNA viruses [14-16]. MVE is responsible for endemic cases of encephalitis in tropical regions of Australia and Papua New Guinea, and occasional epidemics in south-eastern Australia $[17,18]$. Other flaviviruses of major public health concern are the closely related Japanese encephalitis virus (JE), yellow fever virus (YF) and dengue viruses (DEN). Currently, an attenuated vaccine for YF [19], an inactivated 
vaccine for tick-borne encephalitis virus (TBE) [20] and both attenuated [21] and inactivated [22] vaccines for JE are available [23]. Despite the success of the $Y F$ and TBE vaccines it is necessary to improve vaccines against other flaviviruses, particularly $\mathrm{JE}$ and DEN. A Salmonella strain is a promising vaccine vector for this purpose as it induces both cellular and humoral immune responses that may be necessary to confer protection against flavivirus infection.

The flavivirus virion contains three structural proteins: the capsid protein $(\mathrm{C})$, the envelope protein $(\mathrm{E})$ and the membrane protein $(\mathrm{M})$, which is cleaved from the pre-membrane protein (prM) during maturation. The $\mathrm{E}$ protein $[54 \mathrm{kD}]$, located as horizontal dimers on the virion surface, is the carrier of the major antigenic determinants [24-26]. This protein is involved in receptor binding, fusion with cell membranes and is the target antigen for neutralising antibodies. The topology of the E protein of MVE and the location of B-cell epitopes on its surface have been investigated with the use of monoclonal antibodies (MAbs) [27]. The identification and use as a vaccine of a linear Bcell epitope consisting of residues 201-224 of the E protein of MVE are described. This epitope has the ability to induce neutralising antibodies against MVE in vivo. The MVE $\mathrm{E}_{201-224}$ B-cell epitope was expressed in an attenuated Salmonella strain as part of a chimeric flagellin gene and the recombinant vaccine was used to induce a specific immune response to MVE in immunised mice.

\section{Materials and methods}

\section{Bacterial strains, plasmids and media}

The bacterial strains used in this study are shown in Table 1. Salmonella strains were grown at $37^{\circ} \mathrm{C}$ on Luria-Bertani medium (LB) (Oxoid) supplemented with appropriate antibiotics. The pEX plasmids and the host Escherichia coli strain MC1061/pCI857 were as described by Stanley and Luzio [28]. The latter carries the plasmid pCI857 encoding kanamycin resistance and the $t s \mathrm{cI}$ repressor gene of bacteriophage $\lambda$. E. coli strain $\mathrm{MC} 1061 / \mathrm{pCl} 857$ was grown at $30^{\circ} \mathrm{C}$ in $\mathrm{LB}$ medium [29] supplemented with ampicillin $100 \mathrm{mg} / \mathrm{L}$ and kanamycin $40 \mathrm{mg} / \mathrm{L}$ (Sigma).

Plasmid $\mathrm{p} 2 / 1 / 22$ [30] was from an MVE genomic library [31]. It comprised the $1.9-\mathrm{kb}$ plasmid vector
pMT21 (H. V. Huang, Department of Molecular Microbiology, Washington University School of Medicine, St Louis, Missouri, USA) which codes for ampicillin resistance, and the $5^{\prime}$ terminal $5.4 \mathrm{~kb}$ of the MVE genome coding for $\mathrm{C}$, prM, E and the nonstructural proteins; NS1, NS2A, NS2B and half NS3; the complete sequence of $\mathrm{p} 2 / 1 / 22$ has been established [30].

\section{DNA techniques}

Small preparations of plasmid DNA were made by the alkaline lysis method of Birnboim and Doly [32]. Ligations were performed as described by Maniatis et al. [29]. Transformation procedures were performed as by Dower et al. [33]. The Sequenase Version 2.0 sequencing kit (United States Biochemical) was used for sequencing by the method of Sanger et al. [34].

\section{Construction of expression plasmids for mapping the E-8 epitope}

Plasmid pE22-272 (Fig. 1) contained a Taq I fragment $(0.75 \mathrm{~kb})$, which coded for MVE E protein from Asp22 to Val272, from the MVE cDNA clone p2/1/22 [30]. This fragment was first ligated to $A c c$ I-digested M13 mp8 DNA, then cleaved at the Bam HI and Pst I sites which flank the $A c c$ I site in M13 mp8 to produce a 0.8 -kb E gene fragment with $B a m \mathrm{HI}$ and Pst I cohesive ends for ligation to Bam HI- and Pst I-digested pEX plasmids. Plasmid pE146-429 (Fig. 1) contained a partially digested Sau3A fragment $(0.85 \mathrm{~kb})$ coding for E protein from Ser146 to Gly429. This plasmid was obtained from a library of expression plasmids generated by ligating $\mathrm{p} 2 / 1 / 22$, partially digested with $\operatorname{Sau} 3 \mathrm{~A}$, to Bam HI-digested pEX plasmids. pE146-429 was identified by immunoscreening with polyclonal antiMVE antisera and sequence analysis.

A series of deletion plasmids which expressed E fragments of 24-183 amino acids were generated from pE22-272 and pE146-429 (Fig. 1). Construction of these utilised the StuI, NcoI and Pst I sites in the E gene (corresponding to residues 201, 224 and 328, respectively) and the SmaI and Pst I sites in pEX plasmids which flank the $5^{\prime}$ and $3^{\prime}$ ends of $\mathrm{E}$ gene inserts, respectively. Thus, fragments from the $5^{\prime}$ and $3^{\prime}$ ends of the $E$ gene inserts were deleted by restriction enzyme digestion as shown in Fig. 1 and the linearised plasmids isolated on low-melting-

Table 1. E. coli and Salmonella strains

\begin{tabular}{lll}
\hline Strain & Genotype & Source \\
\hline E. coli & & \\
CL447 & hag & B. Stocker \\
Salmonella Dublin & fil::Tn10, $\Delta$ aroA & \\
SL5928 & SL5928/pLS408 & B. Stocker \\
SL5930 & SL5928/pNV291/MVE E $201-224$ & B. Stocker \\
B5127 & SL5928/pNV291/MVE E201-224 wrong orientation & This study \\
B5128 & This study \\
\hline
\end{tabular}


A.

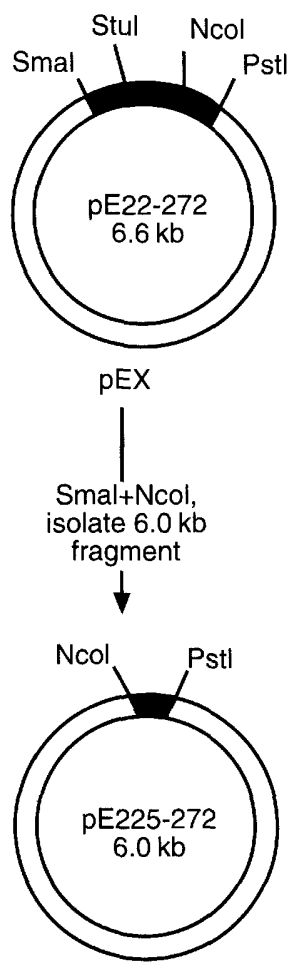

B.
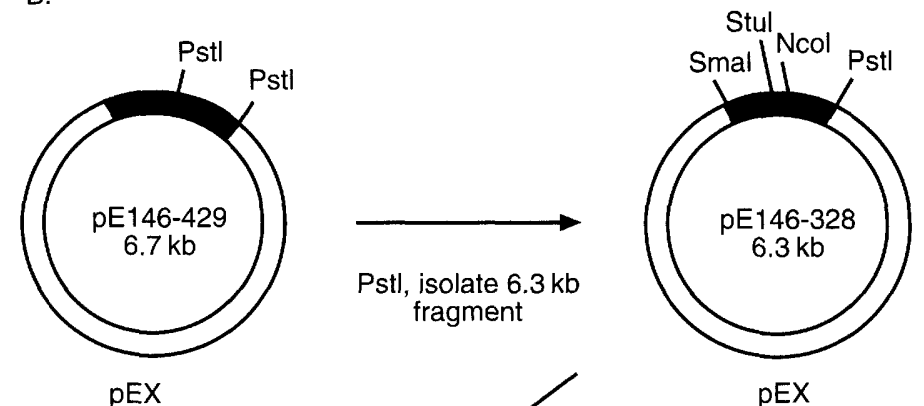

pEX
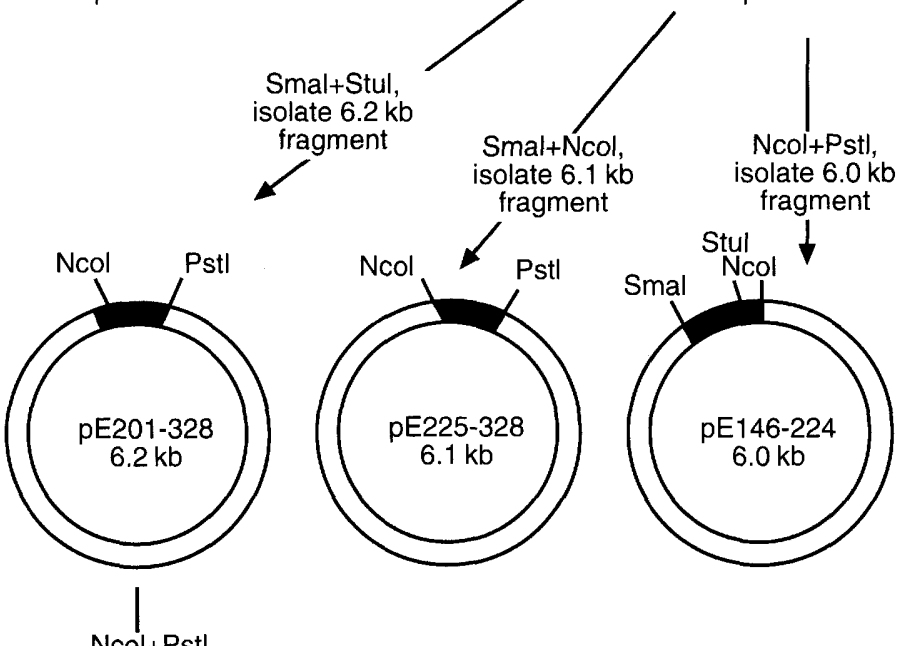

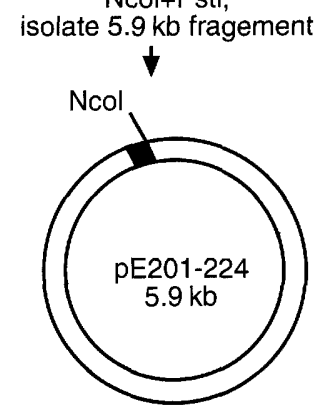

Fig. 1. Construction of expression plasmids for mapping the E-8 epitope. pE22-272 (A) and pE146-429 (B) were used to generate a series of deletion plasmids that expressed E fragments of 24-183 amino acids.

temperature agarose gel, blunt-ended by T4 DNA polymerase and self-ligated. Recombinant $\mathrm{pEX}$ expression plasmids were transformed into $E$. coli strain $\mathrm{MC} 1061+\operatorname{pcl} 857$ [28], incubated at $30^{\circ} \mathrm{C}$ in the presence of ampicillin and kanamycin and selected by immunoscreening with polyclonal anti-MVE antisera. The correct constructs were confirmed by immunoreactivity, restriction endonuclease analysis of plasmid DNA and size of the E- $\beta$-Gal fusion proteins.

\section{Insertion of the MVE $E_{201-224}$ B-cell epitope coding sequence into the salmonella flagellin gene}

A synthetic double-stranded oligonucleotide that encodes the 24 amino acid MVE $E_{201-224}$ B-cell epitope was designed according to Salmonella codon usage (Fig. 2). This construct included a single NruI restriction site. An Asp codon was added to the 3' end of the sequence so that when the oligonucleotide was inserted into the EcoRV site of plasmid pLS408, the site was retained.

The complementary oligonucleotides were annealed and blunt-end ligated to phosphatase-treated, EcoRVdigested DNA of plasmid pLS408. A flagellindeficient E. coli strain, CL447 (Table 1), was transformed with the ligated product and transformants were selected on ampicillin plates. Plasmid DNA from transformants was extracted and screened for the presence of the insert by $N r u \mathrm{I}$ and EcoRI double restriction digests.

\section{Motility tests}

Motility tests were performed on $60 \mathrm{ml}$ of semi-solid agar (Difco) $0.6 \% \mathrm{w} / \mathrm{v}, 30 \mathrm{ml}$ of LB broth and $90 \mathrm{ml}$ of gelatin $16 \% \mathrm{w} / \mathrm{v}$. Colonies were spotted on to individual semi-solid agar plates and incubated at $37^{\circ} \mathrm{C}$ 


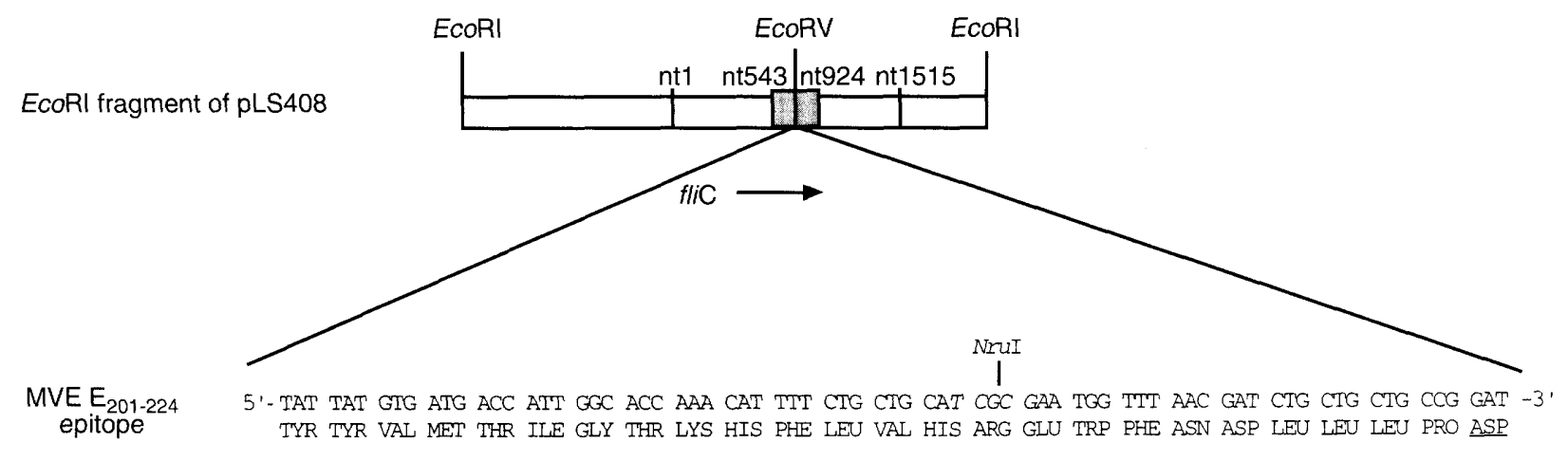

Fig. 2. Structure of the MVE $E_{201-224}$ epitope-flagellin chimeric gene. Plasmid pLS408 is a pUC19 derivative carrying a $3.8-\mathrm{kb} E c o \mathrm{RI}$ fragment that includes the flagellin structural gene $\mathrm{H} 1-d(f i \mathrm{C})$ from serotype Muenchen. Arrow indicates the direction of transcription of the fic. The nucleotide sequence encoding the MVE $\mathrm{E}_{201-224}$ epitope which was inserted in the hypervariable region (shaded segment) is indicated below. The additional amino acid is underlined and the $\mathrm{Nru}$ I restriction site is italicised.

for $16 \mathrm{~h}$. The degree of motility was measured as the distance the colony spread.

\section{Immunoblotting}

Whole-cell lysates were tested for their reactivity with antibodies by immunoblotting after SDS-PAGE. Bacteria $\left(5 \times 10^{7} \mathrm{cfu}\right)$ were boiled in sample buffer and separated on a polyacrylamide $10 \% \mathrm{w} / \mathrm{v}$ gel. For immunoblotting, the gel containing separated proteins was transferred electrophoretically to nitrocellulose membrane [35]. Primary antibodies used to probe Western blots included a mouse monoclonal anti-E8 antibody, specific to the epitope, a rabbit polyvalent $\mathrm{H}$ antibody specific to the flagellin antigen $d$ of Salmonella and polyclonal anti-MVE hyperimmune ascitic fluid (HIAF). Immune complexes were detected with HRP-labelled anti-mouse or anti-rabbit antibodies for the ECL Western blotting detection system (Amersham Corporation).

\section{Immunogold labelling and electron microscopy}

Salmonella strains were negatively stained with uranyl acetate $0.5 \%$, by the method of Ho et al. [36], for electron microscopy. For immunogold labelling, the primary antibody, monoclonal anti-E8, was diluted 1 in 400 in PBS with bovine serum albumin (BSA) $0.4 \%$ $w / v$. Sheep anti-mouse gold conjugate, diluted 1 in 9 was used as secondary antibody. The grids were viewed at magnifications of between 30000 and 100000 with a Hitachi H600 transmission electron microscope.

\section{Purification of fusion proteins}

E. coli cells containing pEX or recombinant plasmids were grown at $30^{\circ} \mathrm{C}$ in $\mathrm{LB}$ medium containing ampicillin $100 \mathrm{mg} / \mathrm{L}$ and kanamycin $40 \mathrm{mg} / \mathrm{L}$ until stationary phase was reached. Cells were diluted in fresh medium to an OD of 0.05 at $630 \mathrm{~nm}$. Incubation was continued at $30^{\circ} \mathrm{C}$ for $1 \mathrm{~h}$ and at $42^{\circ} \mathrm{C}$ for $2 \mathrm{~h}$. Cells were collected by centrifugation at $8000 \mathrm{rpm}$ for $10 \mathrm{~min}$, resuspended in $\mathrm{NaCl} 0.9 \% \mathrm{w} / \mathrm{v}$ to $1 / 20$ th the original volume and lysed by three cycles of freezing in liquid nitrogen and thawing at $30^{\circ} \mathrm{C}$. Lysozyme was added to $125 \mathrm{mg} / \mathrm{L}$ and the extract was held on ice for $20 \mathrm{~min}$ followed by another cycle of freezing and thawing. The lysates were then sonicated for $30 \mathrm{~s}$ and centrifuged for $15 \mathrm{~min}$ at $4^{\circ} \mathrm{C}$. The resulting pellets, which were enriched in fusion proteins, were resuspended in $8 \mathrm{M}$ urea (Ultrapure, Sigma) in $10 \mathrm{~mm}$ Tris$\mathrm{HCl}(\mathrm{pH}$ 7.4). After clarification by centrifugation, fusion protein solutions were dialysed overnight against PBS at $4^{\circ} \mathrm{C}$.

\section{Inoculation of mice}

Fusion proteins ( $10 \mu \mathrm{g}$ each in $50 \mu 1$ of PBS) were mixed with equal volumes of Freund's incomplete adjuvant (FIA, Difco), emulsified by passing through a syringe several times and injected intraperitoneally (i.p.) into groups of five outbred Swiss mice aged 6-8 weeks. Booster injections were given 4 weeks and 9 weeks after the initial injection.

Bacterial clones for immunisation were grown overnight at $37^{\circ} \mathrm{C}$ in $\mathrm{LB}$ containing ampicillin $50 \mathrm{mg} / \mathrm{L}$. These overnight cultures were subcultured ( 1 in 20) and grown to $\log$ phase. Cells were washed twice and resuspended in phosphate-buffered saline. Groups of four $\mathrm{BALB} / \mathrm{c}$ mice were inoculated i.p. with $200 \mu \mathrm{l}$ of $10^{6} \mathrm{cfu}$ on days 1 and 4 . Blood was taken from the retro-orbital plexus before immunisation and then at weekly intervals. Sera were collected from microfuged blood and stored at $-20^{\circ} \mathrm{C}$.

\section{Enzyme-linked immunosorbent assay (ELISA)}

Fusion protein was purified from $E$. coli expressing the recombinant $\mathrm{pEX}$ plasmid $\left(\mathrm{pE}_{201-224}\right)$. This plasmid carries the MVE $\mathrm{E}_{201-224}$ epitope fused to the E. coli $\beta$-gal gene. Reactivity of immune sera with MVE virus or fusion protein was examined by ELISA. Colour development was in $100 \mu \mathrm{l}$ of citrate-phosphate buffer ( $0.1 \mathrm{M}$ citric acid, $\left.0.2 \mathrm{M} \mathrm{Na}_{2} \mathrm{HPO}_{4}\right), \mathrm{H}_{2} \mathrm{O}_{2} \quad 0.0008 \%$ and $o$-phenylene diamine dihydrochloride (OPD). The 
reaction was stopped by the addition of $50 \mu \mathrm{l}$ of $\mathrm{H}_{2} \mathrm{SO}_{4}$ $25 \% \mathrm{v} / \mathrm{v}$ to each well. Plates were read at $490 \mathrm{~nm}$ with an automated plate reader (Deltasoft). Controls comprised sera collected from mice before vaccination.

\section{Plaque reduction neutralisation tests}

Plaque reduction neutralisation tests (PRNT) were used to determine the neutralisation efficiency of the antiMVE mouse sera. Vero cells were grown as monolayers in six-well Linbro plates. Sera were serially diluted two-fold in $150 \mu \mathrm{l}$ of Hank's Balanced Salts Solution (HBSS), $\mathrm{pH} 8$, and incubated at $37^{\circ} \mathrm{C}$ in a $\mathrm{CO}_{2}$ incubator for $1 \mathrm{~h}$ with $200 \mathrm{pfu}$ of MVE-1-51 in $100 \mu \mathrm{l}$ of HBSS. Samples $(100 \mu \mathrm{l})$ of these mixtures were used to infect a cell monolayer, in duplicate. These were incubated for $1 \mathrm{~h}$ in the $\mathrm{CO}_{2}$ incubator with occasional gentle shaking. A 3-ml agar overlay was added to the infected cells in each well and the plates were incubated for 3 days in a $\mathrm{CO}_{2}$ incubator. The cells were then stained with neutral red $0.01 \%$ in HBSS and examined for plaque formation. Control assays were performed with mouse sera taken before vaccination and with polyclonal antibody to MVE.

\section{Results}

\section{Mapping epitope E-8 of MVE by bacterial expression cloning}

The epitope E-8 is one of five topologically related epitopes (E-1a, E-1c, E-1d, E5 and E-8) defined by type-specific, neutralising, and passively protective MVE MAbs $[27,37,38]$. Only MAb E-8 reacted with MVE E protein in Western blots of both unreduced and $\beta$-mercaptoethanol-reduced virus. Thus it was feasible to attempt mapping of the E-8 epitope by bacterial expression of $\mathrm{E}$ protein fragments. Two fragments of MVE E protein, Asp-22-Val-272, encoded in a Taq I restriction fragment, and Ser-146-Gly-429, encoded in a partial Sau3A restriction fragment, were first expressed in $E$. coli as fusion proteins (E22-272 and E146-429) with truncated $\beta$-galactosidase ( $\beta$-gal; $c$. $100 \mathrm{kDa}$ ). The two $\mathrm{E}$ fragments together represented $c$. $80 \%$ of the complete $\mathrm{E}$ sequence (501 amino acids). The construction of the pEX-derived expression plasmids is summarised in Fig. 1.

Reactivity of MAb 6B4A-10 (anti-E-8) with $\beta$ mercaptoethanol-reduced bacterial lysates containing E22-272 and E146-429 fusion proteins was demonstrated in Western blots (Fig. 3). Anti-E-8 reacted with unreduced E22-272 and E146-429 with equivalent intensity (data not shown). Thus, on the basis of these results, E-8 is located in E protein between Ser-146 and Val-272.

To define the E-8 epitope further, expression plasmids pE22-272 and pE146-429 were deleted by restriction endonucleases to generate seven subclones expressing
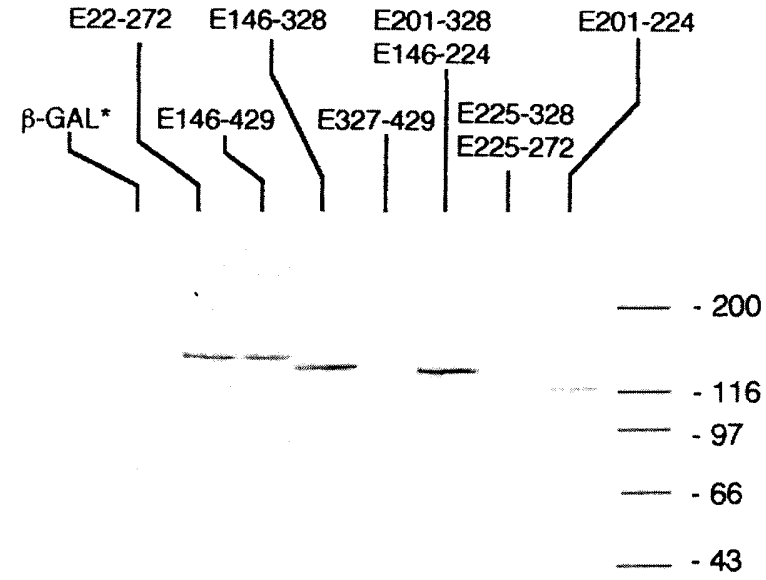

Fig. 3. Reactivity of anti-E-8 MAb with fusion proteins comprising MVE E protein fragments of 24-284 amino acids. Whole bacterial lysates were separated on SDSPAGE $(7.5 \%)$ and analysed by Western blotting with mouse MAbs diluted 1 in 500 ; molecular masses $(\mathrm{kDa})$ are shown on the right.

E protein fragments from 24 to 183 amino acids in length (Fig. 1). The corresponding fusion proteins were of the expected sizes and all reacted with polyclonal anti-MVE hyperimmune ascitic fluid in Western blots (results not shown). Of these fusion proteins, E146-328, E201-328, E146-224 and E201-224 reacted with anti-E-8 in Western blots, while E225-272, E225-328 and E327-429 did not (Fig. 3). However, fusion proteins E201-224 and E146-224 were consistently less reactive than E201328 and E146-328. As the E fragment Tyr-201-Pro224 was present in all of the reactive fusion proteins and not in the unreactive fusion proteins, the dominant determinant of epitope E- 8 is located in the 24 amino acids from Tyr-201 to Pro-224 of the MVE E protein. The marked reduction in reactivity of anti-E- 8 with fusion protein lacking the sequence from Trp-225 to Gln-328 indicates that part or all of this sequence may be required for authentic presentation of epitope E-8.

Partially purified fusion protein E201-224 (c. 95\% purity) was tested for ability to elicit anti-MVE antibodies in mice. The resulting antisera reacted with E201-224 $\beta$-gal fusion protein and MVE in ELISA (maximum titres of 51200 and 400, respectively). However, these antisera lacked any significant neutralisation activity against MVE. Use of a larger fusion protein E22-272 for immunisation gave similar results.

Identification of recombinant Salmonella carrying the chimeric flagellin gene containing the MVE $E_{201-224}$ epitope

Following insertion of the MVE $\mathrm{E}_{201-224} \mathrm{~B}$-cell epitope into the cloned flagellin gene of the Salmonella strain, three clones carrying the recombinant plasmid were identified. The inserts in these plasmids carrying the chimeric flagellin gene were sequenced with two 18-bp 
primers located upstream from the insertion point. A plasmid, pNV291, was identified that had a complete copy of the 25 amino acid encoding insert in the correct orientation. The flagellin-deficient, aroA vaccine strain, serotype Dublin SL5928 (Table 1), was transformed with the recombinant plasmid by electroporation and transformants were selected on ampicillin plates. The strain carrying plasmid pNV29l was designated B5127.

\section{Expression of the chimeric flagellin genes}

The expression of the $E_{201-224}$ B-cell epitope as part of the flagellin protein by the recombinant strain B5127 was demonstrated by Western blotting of whole cell lysates with the E8 MAb and a polyclonal antibody to the flagellin antigen $d$. A protein migrating with an apparent molecular mass of $53 \mathrm{kDa}$ in strain B5127, carrying the $E_{201-224}$ epitope of MVE, was bound by MAb E8 (Fig. 4a). As expected, the MAb did not bind to proteins from strains SL5930 (carrying pLS408; wild-type flagellin) and SL5928 (flagellin deficient), indicating that there was no reactivity of the anti-E8 antibody with any of the salmonella proteins.

The polyclonal antibody specific for the flagellin antigen $d$ also bound the $53-\mathrm{kDa}$ protein of strain B5127, and a protein of $51 \mathrm{kDa}$ in strain SL5930 (Fig. 4b). This indicated that the chimeric flagellin was expressed and contained the $\mathrm{E}_{201-224}$ epitope.

\section{Topological location of the MVE $E_{201-224}$ epitope on the flagella of B5127}

The topology of the B-cell epitope with respect to the flagellum filament in the Salmonella recombinant was detected by immunogold electron microscopy with the mouse MAb, anti-E8, and a gold-labelled goat antimouse IgG as the secondary antibody (Fig. 5). The $\mathrm{MAb}$ bound along the length of the B5127 flagella, indicating that the epitope was present in multiple copies on the surface of the flagella filaments. The antiE8 antibody did not bind to flagella of SL5930 (a control strain) which carries pLS408, encoding a wildtype flagellin.

\section{Motility and electron microscopy of recombinant strains}

Motility tests revealed that the recombinant strain B5127 was non-motile on semi-solid agar. The morphology of the flagella on recombinant strains was observed by electron microscopic examination of negatively stained specimens. Strain B5127 (pNV291) showed some distinguishable differences in flagella morphology compared with wild-type flagella. Cells of strain B5127 had lower numbers of flagella and these were truncated and were often found separated from the bacterial cell. Thus, the chimeric flagella were morphologically and functionally abnormal compared with wild-type flagella. These results suggest that certain sequences inserted into the hypervariable region of the salmonella flagellin gene may impart significant differences in flagella morphology and function.

\section{Immune response in mice to attenuated Salmonella expressing chimeric flagellin containing the MVE $E_{201-224}$ epitope}

To determine if the recombinant Salmonella strain carrying chimeric flagella containing the MVE B-cell epitope could induce an MVE specific immune a

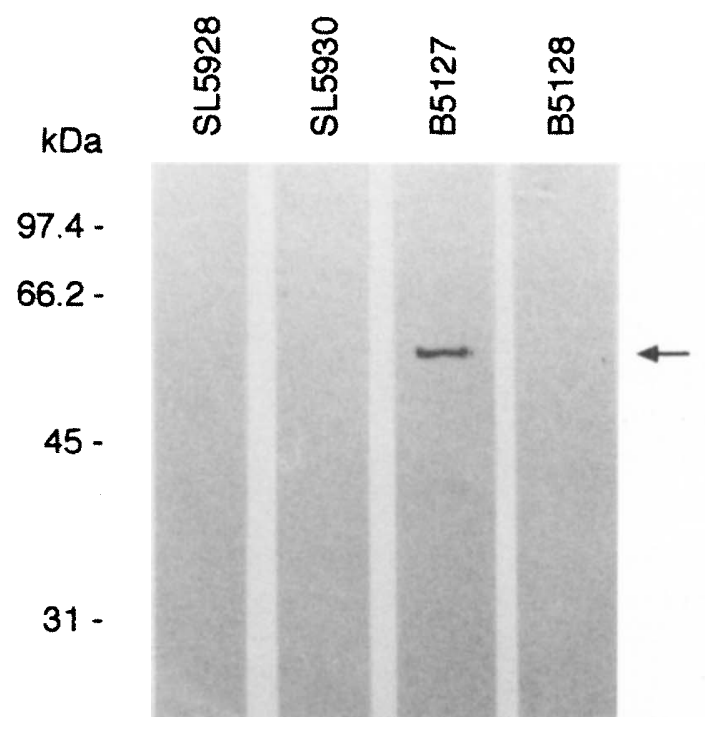

b

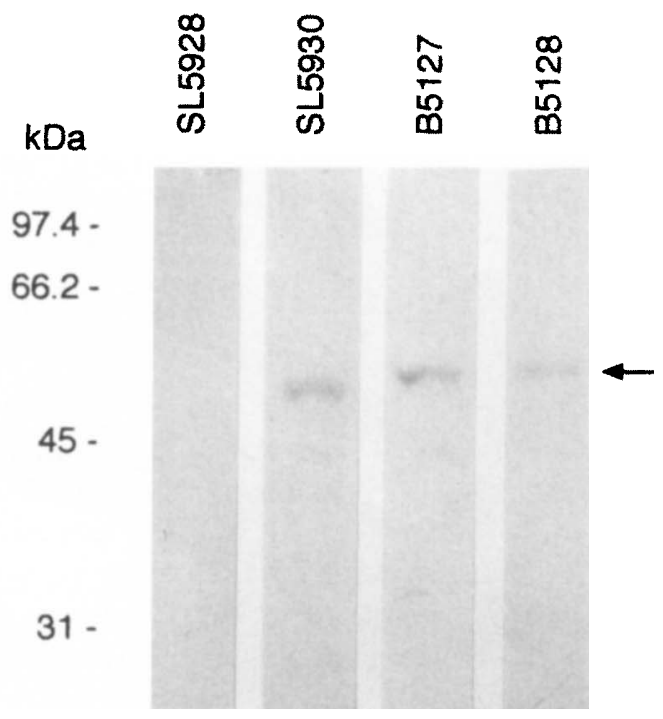

Fig. 4. Western blot showing expression of the MVE $E_{201-224}$ chimeric flagellin protein. Whole bacterial cell lysates of strain B5127 were analysed by Western blotting with either: a, a mouse MAb to the MVE $E_{201-224}$ epitope or b, polyclonal antiserum to flagella antigen $d$. The arrow indicates the increased apparent molecular mass of the B5127 flagellin by the addition of the epitope. 

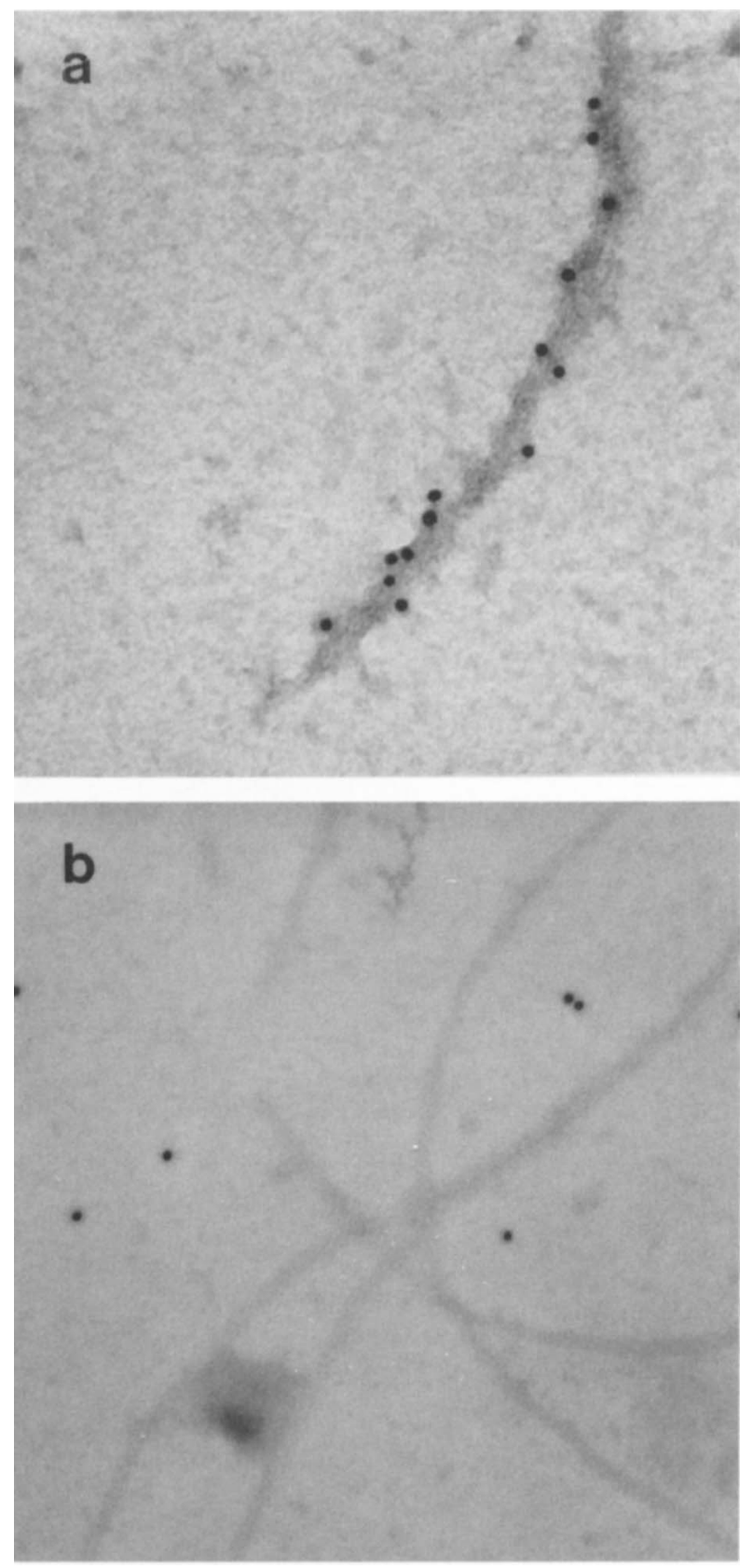

Fig. 5. Location of the MVE $E_{201-224}$ epitope on the surface of the B5127 flagella filament. a, the strain B5127 expressing the chimeric flagellin, $\times 80000$; $\mathbf{b}$, the wild-type flagellin expressing strain, SL5930, $\times 60000$. The presence of gold particles $(10 \mathrm{~nm})$ on the surface of the chimeric flagellin represents the expression of the MVE $E_{201-224}$ epitope.

response in vivo, mice were inoculated i.p. with the recombinant Dublin strain, B5127, or strain SL5930 (control strain). Sera from weekly bleeds were tested for MVE-specific antibodies by ELISA, with the fusion protein containing the epitope and purified MVE as detecting antigens.

Antibody responses are shown in Table 2. Reactivity against the fusion protein was detected in all mice by 2 weeks after the initial inoculation of the recombinant Salmonella strain. The titres increased steadily up
Table 2. Production of MVE specific antibodies by four mice immunised with strain B5127 (MVE $E_{201-224}$ chimeric flagellin)

\begin{tabular}{lcc}
\hline & \multicolumn{2}{c}{ ELISA titre with } \\
\cline { 2 - 3 } $\begin{array}{l}\text { Week after } \\
\text { immunization }\end{array}$ & $\begin{array}{c}\text { fusion protein } \\
10 \mu \mathrm{g} / \mathrm{ml}\end{array}$ & $\begin{array}{c}\text { whole MVE virus } \\
10^{8} \mathrm{pfu} / \mathrm{ml}\end{array}$ \\
\hline 0 & $<1000$ & $<25$ \\
2 & 4000 & 100 \\
3 & 8000 & 100 \\
4 & 16000 & 200 \\
5 & 32000 & 200 \\
6 & 32000 & 400 \\
8 & 16000 & 200 \\
10 & 16000 & 200 \\
12 & 16000 & 50 \\
16 & 8000 & 25 \\
\hline
\end{tabular}

ELISA titres are the highest dilution of serum that yielded three times the absorbance value at $490 \mathrm{~nm}$ of SL5930 control sera.

to a maximum at week 6. No MVE antibody activity was detected in mice inoculated with the control strain SL5930. The antibody titres against whole MVE virus followed a similar pattern but were much lower than those detected against the fusion protein. The peak antibody titre was c. 32000 against fusion protein and c. 400 against the virus.

\section{MVE neutralisation by the anti-epitope $E_{201-224}$ antisera}

It was of interest to determine whether the sera that reacted with MVE in an ELISA neutralised MVE virus infectivity. The results of neutralisation assays (PRNT) with sera obtained 6 weeks after inoculation are represented in Fig. 6. All four mouse antisera neutralised $60-70 \%$ of virus at a dilution of 1 in 5 . Three antisera neutralised $>40 \%$ of virus at a dilution of 1 in 20 . Only one antiserum neutralised $>40 \%$ of virus at a dilution of 1 in 80 . Although a significant neutralising antibody response was obtained in all mice, complete neutralisation of virus was not obtained with any of the antisera.

\section{Discussion}

The experiments in this study were designed to identify a linear B-cell epitope from the E protein of MVE and to examine the ability of this epitope to induce a humoral immune response in vivo, when inserted into the central region of a salmonella flagellin gene and administered as a live vaccine.

To define neutralisation epitopes in the MVE $E$ protein, $\mathrm{E}$ gene fragments fused to the $\beta$-galactosidase coding region were subjected to a series of deletions, and the resulting fusion proteins were characterised and examined for their reactivities with neutralising MAbs to map the epitopes. The bacterially expressed $\beta$-galactosidase fusion proteins allowed the E-8 epitope to be mapped to a sequence of 24 amino 


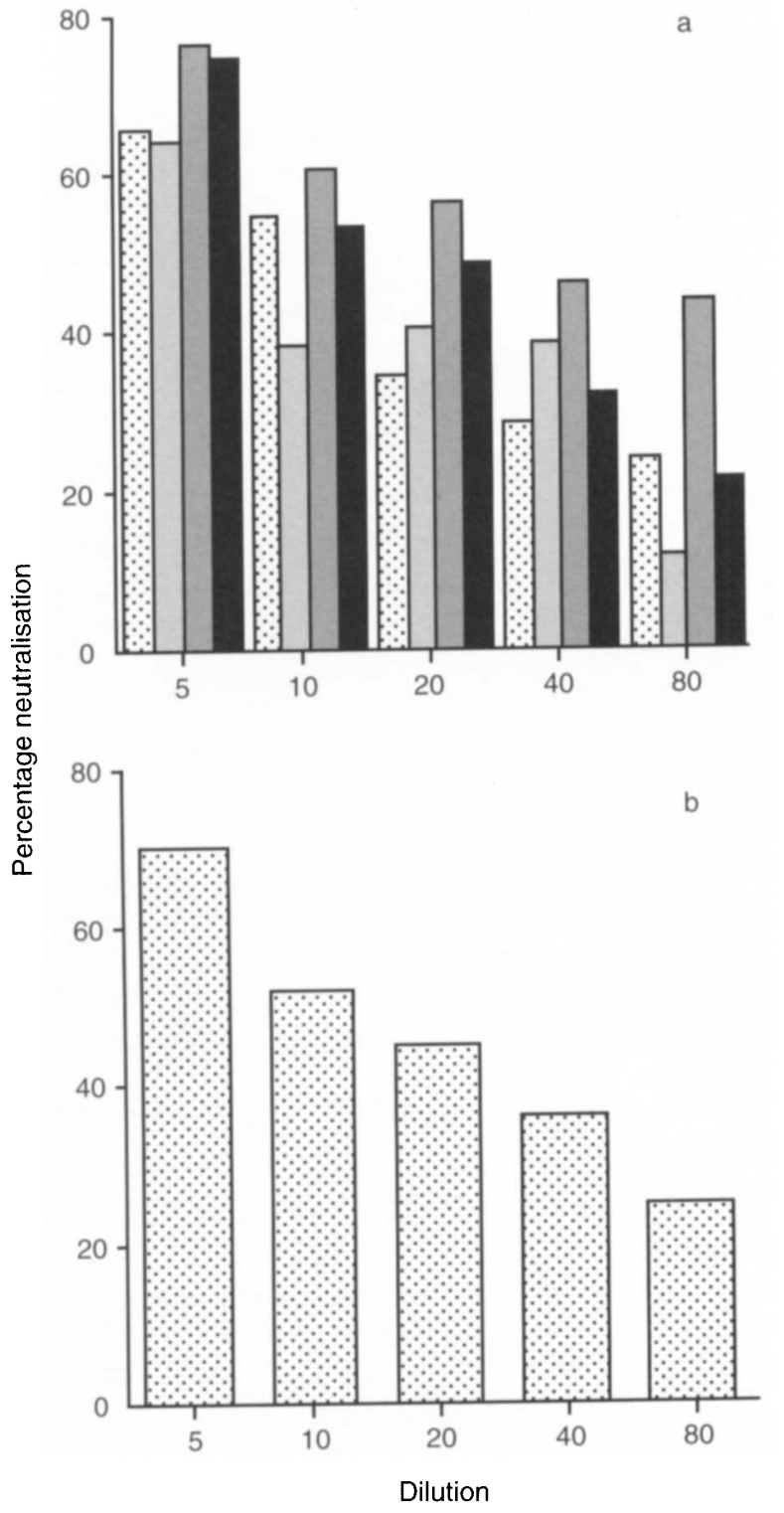

Fig. 6. Virus neutralising activity of sera from mice immunised with strain B5127. Sera from week 6 bleeds were used for PRNT. The percentage neutralisation was taken as the percentage of plaque reduction by sera from mice vaccinated with strain B5127 relative to reduction by sera from mice immunised with strain SL5930. a, individual results of sera at different dilutions from four mice immunised with strain B5127. b, average results of sera at different dilutions from four mice immunised with strain B5127.

acids from residues 201 to 224 . The data are consistent with the results of Guirakhoo et al. [38] that placed E- 8 between residues 200 and 327 on the basis of $\mathrm{MAb}$ reactivity with $\mathrm{E}$ fragments derived by proteolysis. By homology with the $\mathrm{E}$ protein of West Nile (WN) virus [39], E-8 is presumably in a loop formed by the disulphide bond Cys190-Cys288. As reduction of the disulphide bonds had little effect on E-8, it appears to be a linear epitope. Fig. 7 shows the sequence of the MVE E protein from Tyr-201 to Pro224 aligned with that of other flaviviruses. The sequence contains two hydrophobic regions (at the $\mathrm{N}$ - and C-termini) and a hydrophilic central region

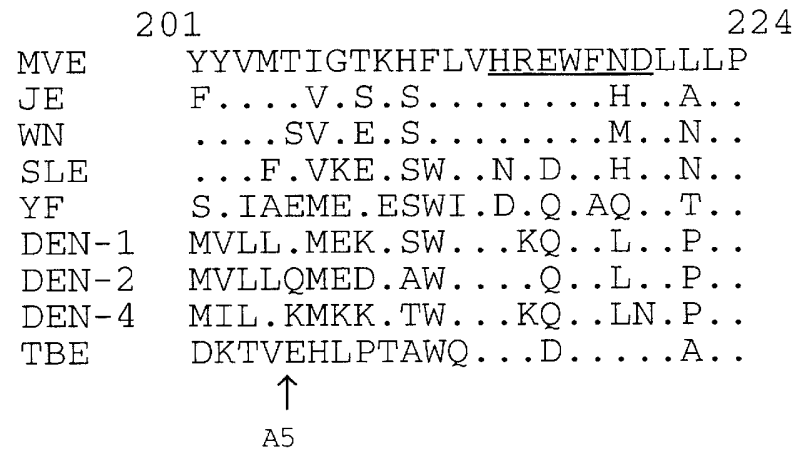

Fig. 7. Amino-acid sequence of the MVE E protein from Tyr 201 to Pro 224. The MVE sequence [30] is shown on the top line with an underlined segment representing a strongly hydrophilic region. Aligned sequences below are for Japanese encephalitis virus (JE) [44], West Nile virus (WN) [45], St Louis encephalitis virus (SLE) [46], yellow fever virus (YF 17D) [47], dengue 1 virus (DEN-1) [48], DEN-2 [49], DEN-4 [50] and tick-borne encephalitis virus (TBE) [42]. The single letter aminoacid code is used; dots represent amino-acid residues identical to MVE at similar positions. The arrow indicates the A5 neutralisation determinant of TBE.

(underlined in Fig. 7). As the E-8 MAb cross-reacts in ELISA with JE, SLE and $\mathrm{WN}$ and also in protection assays in mice with JE and SLE, the corresponding epitope is likely to show considerable homology between members of the MVE serocomplex. The sequence homology in the region 201-224 between MVE and JE, WN or SLE is 75, 75 and $58 \%$ respectively. Homology is considerably higher at the $\mathrm{C}$-terminal end than overall. As cross-reaction occurs with SLE (which shows c. $70 \%$ homology in the Cterminal 13 amino acids and only $45 \%$ in the $\mathrm{N}$ terminal section), it seems likely that the major binding determinants of E-8 are located in the Cterminal half (residues 212-224). The sequence of amino acids in this region should provide good targets for further mapping of E-8 by peptide analysis.

From competitive binding studies of anti-E-8 with other MAbs against MVE [27], it has been shown that E-8 overlaps with epitopes E-1a, E-1c, E-1d and E-5, and is spatially distinct from epitopes E-3, E-4b, E-6 and $E-7$. These data suggest that a cluster of epitopes (E-1a, E-1c, E-1d, E-5 and E-8), most of which induce neutralising antibodies, form a domain in the $\mathrm{E}$ protein of MVE [41]. The epitope E-8 is in close proximity to the positions of the A4 and A5 neutralisation determinants of TBE, which have been mapped to residues 233 and 207 of the gfeah sheet of domain II, respectively, on the three-dimensional structure of the TBE E protein [40-42]. Domain II has been shown to comprise two discontinuous segments (residues 50-125, residues 200-250) in the disulphide-rich regions of TBE E protein, and is active in inducing neutralising and haemagglutination-inhibiting antibodies [41]. Significantly, the cluster of MVE neutralisation epitopes, including E-8 and E-1c [27], map to the same domain, suggesting conservation of 
structure as well as function across the family of flaviviruses.

As the antisera induced by the fusion protein E201224 lacked significant MVE neutralising ability, it was of interest to express the epitope E- 8 in a Salmonella strain in an attempt to induce a neutralising antibody response in mice. Also, because epitope E-8 is encompassed by a relatively short linear peptide sequence it was suitable for expression in the flagellin of an attenuated Salmonella strain. The chimeric flagellin expressed by the Dublin recombinant strain was demonstrated to contain the $E_{201-224}$ sequence. This epitope was situated in a region of the flagellin sequence that specifies the flagellar serotype and, therefore, is considered to be relatively tolerant of amino-acid deletions and substitutions [43]. Also, the epitope is relatively small when compared with the 500 amino-acid length of the native flagellin. For these reasons, the resulting chimeric flagellin was expected to form normal flagella. Expression of the chimeric flagellin by the recombinant strain was confirmed by Western blotting of whole cell lysates and the location of the epitope as part of the flagellar filament was demonstrated by immunogold electron microscopy. Electron microscopy showed that the hybrid flagellin had been exported to the bacterial surface and assembled into flagella-like filaments. However, the ultrastructural appearance of the flagella was abnormal. The flagella were truncated and present in very small numbers on the recombinant Salmonella strain carrying the MVE B-cell epitope. It was not surprising then that bacteria expressing the chimeric flagella were non-motile in semi-solid medium. In spite of the functional abnormality of the flagella, the chimera generated a significant humoral immune response in vivo. These data suggest that motility and immunogenicity are not necessarily associated, particularly when the vaccine is administered intraperitoneally. It may be possible to restore motility in the non-motile recombinant strain by transforming the strain with a plasmid encoding normal flagellin. This in turn may enhance the potential for its use as an orally administered vaccine.

Mice immunised with the recombinant bacteria generated specific antibodies that reacted with the MVE E-8 epitope- $\beta$-galactosidase fusion protein and the intact MVE virus. The MVE specific immune response increased until 6 weeks after the initial immunisation. However, the MVE specific antibodies only partially neutralised the infectivity of the virus in vitro. Incomplete neutralisation may be an inherent property of the E-8 epitope as in our hands the anti-E$8 \mathrm{mAb}$ did not completely neutralise MVE in vitro (unpublished data). Because anti-E-8 antibody crossreacts with MVE, SLE, JE and $\mathrm{WN}$, this epitope may be of use in generating a common vaccine for a significant group of flaviviruses. It would be interesting to test the protective effect of the recombinant
Salmonella strain carrying the MVE E-8 epitope in an animal model challenged with these flaviviruses.

We thank B. Stocker for providing the plasmid pLS408 and Salmonella strains and J. T. Roehrig for his generous gift of the anti-E-8 MAb. This work was supported by grants from the ANU Faculties Research Grants Scheme and from the Vertebrate Biocontrol Centre, Canberra.

\section{References}

1. Curtiss RJ, Hassan O, Herr $\mathrm{J}$ et al. Nonrecombinant and recombinant avirulent salmonella vaccines. Proceedings of the Symposium Recombinant and Synthetic Vaccines. New Delhi, India. 1992.

2. Cárdenas L, Clements JD. Stability, immunogenicity and expression of foreign antigens in bacterial vaccine vectors. Vaccine 1993; 11: 126-135.

3. Stocker BAD, Newton SM. Immune responses to epitopes inserted in salmonella flagellin. Int Rev Immunol 1994; 11: $167-178$.

4. Hoiseth SK, Stocker BAD. Aromatic-dependent Salmonella typhimurium are non-virulent and effective as live vaccines. Nature 1981; 291: 238-239.

5. Dougan G, Maskell D, Pickard D, Hormaeche C. Isolation of stable aroA mutants of Salmonella typhi Ty2: properties and preliminary characterization in mice. Mol Gen Genet 1987; 207: 402-405.

6. Robertsson JÄ, Lindberg AA, Hoiseth SK, Stocker BAD. Salmonella typhimurium infection in calves: protection and survival of virulent challenge bacteria after immunization with live or inactivated vaccines. Infect Immun 1983; 41: 742-750.

7. Mukkur TKS, McDowell GH, Stocker BAD, Lascelles AK. Protection against experimental Salmonellosis in mice and sheep by immunisation with aromatic-dependent Salmonella typhimurium. J Med Microbiol 1987; 24: 11-19.

8. Smith BP, Reina-Guerra M, Hoiseth SK et al. Aromaticdependent Salmonella typhimurium as modified live vaccine for calves. Am $J$ Vet Res 1984; 45: 59-66.

9. Majarian WR, Kasper SJ, Brey RN. Expression of heterologous epitopes as recombinant flagella on the surface of attenuated Salmonella. In: Vaccine 89. Cold Spring Harbor, NY, Cold Spring Harbor Laboratory Press. 1989: 277-281.

10. Newton SMC, Jacob CO, Stocker BAD. Immune response to cholera toxin epitope inserted in Salmonella flagellin. Science 1989; 244: 70-72.

11. Verma NK, Ziegler HK, Stocker BAD, Schoolnik GK. Induction of a cellular immune response to a defined T-cell epitope as an insert in the flagellin of a live vaccine strain of Salmonella. Vaccine 1995; 13: 235-244.

12. Verma NK, Ziegler HK, Wilson $M$ et al. Delivery of class I and class II MHC-restricted T-cell epitopes of listeriolysin of Listeria monocytogenes by attenuated Salmonella. Vaccine 1995; 13: 142-150.

13. Newton SM, Manning WC, Hovl M, Stocker BAD. Aromaticdependent Salmonella with foreign epitope insert in flagellin as live vaccine. In: Vaccines 90. Cold Spring Harbor, NY, Cold Spring Harbor Laboratory Press. 1990: 439-445.

14. Westaway EG, Brinton MA, Gaidamovich SY et al. Flaviviridae, Intervirology 1985; 24: 183-192.

15. Marshall ID. Murray Valley and Kunjin encephalitis. In: Monath TP (ed) The arboviruses: epidemiology and ecology. Boca Raton, FL, CRC Press. 1988: 151-189.

16. Chambers TJ, Hahn, CS, Galler R, Rice CM. Flavivirus genome organization, expression, and replication. Annu Rev Microbiol 1990; 44: 696-688.

17. Doherty RL. Arthropod-borne viruses in Australia, 1973-1976. Aust J Exp Biol Med Sci 1977; 55: 103-130.

18. French EL. A review of arthropod-borne virus infections affecting man and animals in Australia. Aust $J$ Exp Biol Med Sci 1973; 51: 131-158.

19. Theiler M, Smith HH. The effect of prolonged cultivation in vitro upon the pathogenicity of yellow fever virus. $J$ Exp Med 1937; 65: 767-786.

20. Kunz C, Heinz FX, Hofmann H, Immunogenicity and reactogenicity of a highly purified vaccine against tick-borne encephalitis. J Med Virol 1980; 6: 103-109. 
21. Yu YX, Zhang GM, Guo YP, Ao J, Li HM. Safety of a liveattenuated Japanese encephalitis virus vaccine (SA-14-14-2) for children. Am J Trop Med Hyg 1988; 39: 214-217.

22. Okuda K, Itoh K, Miyake K, Morita M, Ogonuki M, Matsui S. Purification of Japanese encephalitis virus vaccine by zonal centrifugation. J Clin Microbiol 1975; 1: 96-101.

23. Hill AB, Lobigs $M$, Blanden RV, Kulkarni A, Mullbacher A. The cellular immune response to Flavivirus. In: Thomas DB (ed) Viruses and the cellular immune response. Marcel Dekker, Inc. 1993: $363-387$

24. Heinz FX, Mandl C, Holzmann H, Guirakhoo F, Tuma W, Kunz $\mathrm{C}$. The antigenic structure and function of the flavivirus envelope protein E. 2nd International Symposium on Positive Strand Viruses, Vienna, Austria. 1989.

25. Mandl CW, Guirakhoo F, Holzmann H, Heinz FX, Kunz C. Antigenic structure of the flavivirus envelope protein $\mathrm{E}$ at the molecular level, using tick-borne encephalitis virus as a model. $J$ Virol 1989; 63: 564-571.

26. Mathews JH, Roehrig JT, Brubaker JR, Hunt AR, Allan JE. A synthetic peptide to the $\mathrm{E}$ glycoprotein of Murray Valley Encephalitis Virus defines multiple virus-reactive T- and B-cell epitopes. J Virol 1992; 66: 6555-6562.

27. McMinn PC, Lee E, Hartley S, Roehrig JT, Dalgarno L, Weir RC. Murray Valley encephalitis virus envelope protein antigenic variants with altered hemagglutination properties and reduced neuroinvasiveness in mice. Virology 1995; 211: $10-20$.

28. Stanley KK, Luzio JP. Construction of a new family of high efficiency bacterial expression vectors: identification of cDNA clones coding for human liver proteins. EMBO $J$ 1984; 3: $1429-1434$.

29. Maniatis T, Fritsch EF, Sambrook J. Molecular cloning; a laboratory manual. Cold Spring Harbor, NY, Cold Spring Harbor Laboratory. 1982: 16-17.

30. Dalgarno L, Trent DW, Strauss JH, Rice CM. Partial nucleotide sequence of the Murray Valley encephalitis virus genome. comparison of the encoded polypeptides with yellow fever virus structural and non-structural proteins. $J$ Mol Biol 1986; 187: 309-323.

31. Rice CM, Dalgarno L, Galler R, Hahn YS, Strauss EG, Strauss $\mathrm{JH}$. Molecular cloning of flavivirus genomes for comparative analysis and expression. In: Bauer H, Klenk H-D, Scholtissek $\mathrm{C}$ (eds) Modern trends in virology. Berlin: Springer-Verlag. 1988: 83-97.

32. Birnboim HC, Doly J. A rapid alkaline extraction procedure for screening recombinant plasmid DNA. Nucleic Acids Res 1979; 7: 1513-1523.

33. Dower WJ, Miller JF, Ragsdale CW. High efficiency transformation of E. coli by high voltage electroporation. Nucleic Acids Res 1988; 16: 6127-6145.

34. Sanger F, Nicklen S, Coulson AR. DNA sequencing with chain-terminating inhibitors. Proc Natl Acad Sci USA 1977; 74: $5463-5467$.

35. Towbin H, Staehelin T, Gordon J. Electrophoretic transfer of proteins from polyacrylamide gels to nitrocellulose sheets: procedure and some applications. Proc Natl Acad Sci USA
1979; 76: 4350-4354.

36. Ho ASY, Mietzner TA, Smith AJ, Schoolnik GK. The pili of Aeromonas hydrophila: identification of an environmentally regulated "minipilin". J Exp Med 1990; 172: 795-806.

37. Hawkes RA, Roehrig JT, Hunt AR, Moore GA. Antigenic structure of the Murray Valley encephalitis virus E glycoprotein. J Gen Virol 1988; 69: 1105-1109.

38. Guirakhoo F, Bolin RA, Roehrig JT. The Murray Valley encephalitis virus prM protein confers acid resistance to virus particles and alters the expression of epitopes within the R2 domain of E glycoprotein. Virology 1992; 191: 921-931.

39. Nowak T, Wengler G. Analysis of disulfides present in the membrane proteins of the West Nile flavivirus. Virology 1987; 156: $127-137$.

40. Guirakhoo F, Heinz FX, Kunz C. Epitope model of tick-borne encephalitis virus envelope glycoprotein $\mathrm{E}$ : analysis of structural properties, role of carbohydrate side chain, and conformational changes occurring at acidic pH. Virology 1989; 169: $90-99$.

41. Rey FA, Heinz FX, Mandl C, Kunz C, Harrison SC. The envelope glycoprotein from tick-borne encephalitis virus at $2 \AA$ resolution. Nature 1995; 375: 291-298.

42. Mandl CW, Heinz FX, Kunz C. Sequence of the structural proteins of tick-borne encephalitis virus (Western subtype) and comparative analysis with other flaviviruses. Virology 1988; 166: $197-205$.

43. Wei L-N, Joys TM. Covalent structure of three phase-1 flagellar filament proteins of Salmonella. J Mol Biol 1985; 186: $791-803$.

44. McAda PC, Mason PW, Schmaljohn CS, Dalrymple JM, Mason TL, Fournier MJ. Partial nucleotide sequence of the Japanese encephalitis virus genome. Virology 1987; 158: $348-360$.

45. Castle E, Nowak T, Leidner U, Wengler G, Wengler G. Sequence analysis of the viral core protein and the membraneassociated proteins V1 and NV2 of the flavivirus West Nile virus and of the genome sequence of these proteins. Virology 1985; 145: $227-236$

46. Trent DW, Kinney RM, Johnson BJB et al. Partial nucleotide sequence of $\mathrm{St}$ Louis encephalitis virus RNA: structural proteins, NS1, 2a and 2b. Virology 1987; 156: 293-304.

47. Rice CM, Lenches EM, Eddy SR, Shin SJ, Sheets RL, Strauss $\mathrm{JH}$. Nucleotide sequence of yellow fever virus: implications for flavivirus gene expression and evolution. Science 1985; 229: $726-733$.

48. Mason PW, McAda PC, Mason TL, Fournier MJ. Sequence of the dengue-1 virus genome in the region encoding the three structural proteins and the major nonstructural protein NS1. Virology 1987; 161: 262-267.

49. Deubel V, Kinney RM, Trent DW. Nucleotide sequence and deduced amino acid sequence of the structural proteins of dengue type 2 virus, Jamaica genotype. Virology 1986; 155: $365-377$.

50. Zhao B, Mackow E, Buckler-White A et al. Cloning fulllength dengue type 4 viral DNA sequences: analysis of genes coding for structural proteins. Virology 1986; 155: 77-88. 